\title{
Women and Girls Safety and Security in Public Transport
}

\author{
Emebet Teshome Kebede \\ Faculty of Environment, Gender and Development Studies, College of Agriculture, Hawassa University, \\ P.O.BOX 1627 HAWASSA, SNNPRS, ETHIOPIA \\ Deribe Kaske Kacharo \\ Faculty of Environment, Gender and Development Studies, College of Agriculture, Hawassa University, \\ P.O.BOX 05 HAWASSA, SNNPRS, ETHIOPIA \\ Tesfaye Woltamo \\ Faculty of Environment, Gender and Development Studies, College of Agriculture, Hawassa University, \\ P.O.BOX 05 HAWASSA, SNNPRS, ETHIOPIA
}

\begin{abstract}
Women and girls are among the commuters for different purposes. Commuting has been shown to have negative consequences like violence on travelers particularly for women and girls. Violence against women and girls is a major public health problem globally, particularly in developing countries including Ethiopia. The current study was conducted with the aim of assessing the women's and girls' safety and security in public transport services and to identify factors that contribute to violence against women and girls. For this purpose, multistage sampling techniques were employed. Using the probability sampling technique, 199 respondents were selected. Interview schedule, key informant interviews, and focus group discussions were used as data collection instruments. Data analysis was done using both descriptive and inferential statistics. The major finding of the study shows that $50.8 \%$ of women and girls have experienced at least one type of violence while using public transport. The results of the binary logistic model indicated that six variables were found significantly contribute to violence against women and girls in public transport. Therefore, cities have to focus on developing gender-sensitive public transport service plans and policies that consider the special needs of women and girls in public transportation service systems.
\end{abstract}

Keywords: violence; women; girls; safety; security; public transport

DOI: $10.7176 /$ RHSS/10-9-06

Publication date:May $31^{\text {st }} 2020$

\section{Introduction}

Too many individuals travel every day in cities using public transport. Transportation systems function to move people or goods from one place to another as an attempt to cope with geographical and topographical distance obstacles (Farida, 2018). According to (Divall and Bond, 2017), transportation contributes to the spatial, social, and economic evolution of cities. Also the pPublic transport can be considered as the lifeblood of the state economy, as most urban dwellers, especially women and girls, depend on public transport to commute for various purposes (Sham, Omar, and Dia Widyawati, 2018). Women and girls are among the commuters for different purposes like work, education and other important social, economic, and political activities (Choudhary, Dube, and Verma, 2018). Furthermore, commuting has been shown to have negative consequences like violence on travellers, particularly for women and girls. Gender-Based Violence (GBV) is recognized as a widespread international public health and human rights issue (IASC, 2017). Violence against women and girls (VAWG) is a major public health problem globally, particularly in developing countries, including Ethiopia.

Women in most developing cities have been witnessed an increase in the number of threats to urban safety and security in public transport (Choudhary et al., 2018). Gender does not seem to be a specific factor when it comes to safety rail issues. Security, on the other hand, is a different matter. Security implies protecting transport users against malicious actions and, or, behaviors. Women are a prime target for a number of reasons, often due to the fact that most societies are traditionally patriarchal(ITF, 2018). A study done in Chennai state that $66 \%$ of surveyed respondents had been sexually harassed while commuting (Choudhary et al., 2018). Women, Compared to men, experience a unique set of threats, fears, insecurities, and interactions with the urban environment. In cities across the world, women face a near-constant fear of sexual violence - harassment and/or assault while traveling or in public space (Korn, 2018).Fear of victimization and crime is quite widespread among women. Almost every fear of crime survey reports that women are much more fearful of crime than men, while the fear of rape and serious violence from men may lie in the back of many women's minds, feminist scholars also argue about an existing continuity of violence against women, which includes intimidation, groping, sexual comments and harassment, threats, and other nuisance crimes with sexual undertones (Mineta Transportation Institute, 2009). There is a need to provide the most safe and secure option of travel to women and girls. Safety on the public transportation system enables women to leave their workplace at the time convenient to them; flexible working 
hours are appealing for women, who are more likely than men to combine paid work with unpaid home care work (Asian Development Bank, 2015).

The current study was conducted with the aim of assessing women and girls safety and security in public transport services and to identify factors that contribute to VAWG. Gender is rarely an issue considered with regard to transportation policy and planning; similarly, transportation is rarely included in the gender policy agenda. Thus, the "gender and transportation" field is a somewhat new concept (Aloul, Naffa, \& Mansour, 2019). There are few studies have been conducted in developing countries including Ethiopia about how traveling in public transport related to VAWG (Action Aid 2011; Women's Empowerment Link 2015; Action Aid 2016). Research related to VAWG in public spaces, especially in public transport services, are conducted by international and some national organizations that have mandate and the capacity to promote, respect, and fulfill women's rights both in private and public life (UN Women, 2013); (UN Women, 2014); (Asian Development Bank, 2015); and Women's empowerment link 2015; Action Aid 2016 ). This shows that the subject matter of this study is a recent phenomenon and very uncommon to be researched by concerned bodies and individual researchers in all parts of the world. Regarding Ethiopia not limitations but scarcity of research exists. It is difficult to find research or any documented evidence regarding VAWG in public transport. Of course, as a country, not only violence in the public domain but also even violence in the private domain has not been documented properly. The 2016 Ethiopian Demographic and Health Survey have tried to document the prevalence and forms of VAW in the country. According to this survey among women aged $15-49$ years that is $23 \%$ have experienced physical violence and $10 \%$ have experienced sexual violence (Ethiopia Central Statistical Agency, 2016).

Generally, reliable global statistics on VAWG in public spaces and transport infrastructure are limited (Fraser, Viswanath, \& Maclean, 2017). However, available studies show high levels of VAWG in public transport and adjacent public spaces in many cities around the world (Kakal \& Iyot, 2015). Available Studies have shown that $65 \%$ of women in Mexico, 83 \% of women in Egypt, $90 \%$ of women in Papua New Guinea, and 54\% of women in Kenya have experienced some form of Violence on public transport (ActionAid, 2011) (United Nations, 2015). A survey on women's safety on transport also found that 6 of 10 women in major Latin American cities had been physically harassed while using transport (Fraser et al., 2017). Studies have shown that women who use public transport are at risk of sexual harassment and other forms of sexual violence, including verbal harassment, extortion, inappropriate touching, and indecent exposure and rape (UN Women, 2014). A study conducted by Hollaback and Cornell University, which included 16,600 interviews from 22 countries, concluded that 80-90\% of women had been harassed in public (Aloul et al., 2019).

Women have the right to enjoy all their freedoms equally with men in both private and public spaces. However, women experience violence in public places that include streets, public transport, parks, schools, markets, workplaces, public sanitation facilities, and their own neighborhoods (WEL, 2015). According to the UN Women (2014), VAWG committed in public transport constitutes $19 \%$ of VAWG that are committed in public spheres.

Public transport is an important enabler in accessing the public sphere without which women may be kept away from all important economic, social, and political activities (UN Women, 2014). Globally, women use public transport more than men (WORLD BANK, 2016). A study conducted by the Australian Bureau of Statistics found that women of all ages were more likely than men to use public transportation for their usual journey to work or study (Australian Bureau of Statistics, 2009) - Unsafe public transport limits women's rights and freedoms as equal citizens to access and enjoy their neighborhoods and cities and their mobility and freedom of movement as they avoid certain places, times, routes, and modes of public transportation (ActionAid, 2011). It is argued that as women depend much more on public transport, ensuring women's safety and security, their ability to get to their jobs, and to get their kids to a school in a safe manner is absolutely essential and need the focus of all stakeholders (WORLD BANK, 2016).

Since the regime change in 1991, the Ethiopian government has issued a number of laws that promote the rights of women. However, it is said that although the national constitution, family law, and criminal codes all contain articles that protect women from various forms of violence, women's vulnerability and risks in urban spaces are not sufficiently addressed (ActionAid, 2011).

This time is the era of sustainable development goals (SDG) that magnify the importance of gender equality to achieve all its 17 development goals. Thus, the elimination of all forms of VAWG in both the public and private spheres is one of the main perquisites to achieve gender equality, which is one of the major SDG (United Nations, 2015). It is more, making cities and human settlements inclusive, safe, resilient, and sustainable is also another development agenda stated under SDG 11 with a target that directly contributes to addressing women and girls' safety in public spaces (Fraser et al., 2017).

\section{Methodology}

The research study was conducted in Hawassa City, which is located in southern Ethiopia on the shores of Lake Hawassa in the Central Rift Valley of Ethiopia. The rationale for selecting Hawassa city was because of the fact that it is the largest, better developed, and the only metropolitan city in southern Ethiopia. In addition to this, the 
growth of the city will also bring the expansion and introduction of new and additional transport facilities in the future that needs consideration about the safety and security of women commuters.

\subsection{Research Design and Procedure for Participant Recruitment}

The research design employed a mixed approach using both qualitative and quantitative methods and a crosssectional survey. The study population was all of women and girls aged from 15-60 and public transport users. Totally 199 sample respondents were selected randomly for interviews.

\subsection{Data Collection}

Primary data were collected using an interview schedule; in addition, both Focus Group Discussions (FGDs) and Key Informants Interview (KII) were also used. Secondary data cover annual and periodic reports as well as records from state actors and non-state actors like associations of privately owned public transport service providers.

\subsection{Data Analysis}

Both descriptive and inferential statistics were used as analytical tools. The degree of relationship between several explanatory variables and VAWG in public transport was analyzed using statistical techniques such as bi-variable and multivariable binary logistic regression models. The dependent variable is VAWG in public transport and it has a dummy nature taking a value of ' 1 ' if a woman or a girl experienced any form incident of violence while travelling in public transport and ' 0 ' otherwise.

\section{Results and Discussion}

The sampled respondents were categorized into two categories: those who experienced violence and nonexperienced. According to the study results, about 50.8\% of women and girls have experienced at least one form of violence. This finding is similar to that of a study from Kenya that found out the prevalence of VAWG in the transport sector is 54\% (WEL, 2015). On the other hand, the findings of this study has widely difference from those of studies in Asian countries like Papua New Guinea, Pakistan, and Azerbaijan, where the prevalence of VAWG in the transport sector is $90 \%, 78 \%$, and $81 \%$, respectively, (UN Women, 2013); (Asian Development Bank, 2015). This difference might have occurred because of the socio-economic and cultural differences existing between the countries.

\subsection{Socio-Demographic Characteristics of the Respondents}

The results in Table1 indicate that the average, minimum, and maximum age of respondents are $28.29,16$, and 48, respectively. Of the total sampled respondents, the majority $(61.3 \%)$ of them were found in the age group of 15 29 and followed by 30-44 (31.2\%) age categories (see Table 1). Regarding marital status, the majority of 101 (50.8\%) were single, $70(35.2 \%)$ were married women, and 28 (14.1\%) were separated.

Generally, respondents had better access to education, accordingly 79 (39.7\%) of the respondents had a secondary level of education and $30.7 \%$ were those who are graduates with a minimum of first degree. On the other hand, 19.6\% were diploma holders (see Table 1).

\subsection{Types of Violence}

Regarding the types of violence, respondents were asked to state their personal experiences of physical violence, sexual violence, and psychological violence by giving a list of incidents that constitute each form of violence. As indicated in Table 2, out of the total respondents those who experienced violence, $87(86.1 \%)$ experienced sexual violence, $84(83.2 \%)$ of the respondents had experienced psychological violence, and $75(74.3 \%)$ experienced physical violence.

The most common types of incidents that constitute physical violence are dragging 61(60.4\%), throwing something that could hurt a woman 45(44.6\%), Coercion to board against one's wish 41(40.6\%), push shoving and pulling hair or cloth $13(12.9 \%)$, and Coercion to board against one's wishes $41(40.6 \%)$. According to a study conducted in Baku, Azerbaijan Eight in ten women (81\%) reported having experienced sexual harassment, with a quarter of these (26\%) reporting it as an almost daily occurrence and around four in ten had experienced physical harassment(Jafarova, Campbell, \& Rojas, 2014). A study conducted in Dhaka, Bangladesh revealed that $41 \%$ had been physically harassed or groped on public transport by male passengers, drivers, and/or conductors(Rahman, 2010). Similarly, a study conducted by Secretaría de la Mujer in 2012 in Bogotá, Columbia, reported that $64 \%$ of women had experienced unwanted sexual touching on public transport(Jaramillo, 2014). 83 percent of Egyptian women and $98 \%$ of foreign women surveyed reported experiencing sexual harassment, most often on the streets and on public transport (Aliyaa, Hassan, \& Komsan, 2008). According to a study on 'Matutu': public passenger vehicles (privately owned vans and mini-buses) in Nairobi Kenya, women described being indecently assaulted, groped, rubbed against, having their tops looked down, and being ejaculated on. Rape on matutu is also a crime 
that 'many Kenyan women have suffered' either by hijackers or the men who work on matutu(Mungai \& Samper, 2006)(Gekoski et al., 2015).

As indicated in Table 3, the most common incident of sexual violence was staring 68(67.3\%), obscene gestures $61(60.4 \%)$, making noise, whistling or cat calling 50(49.6\%), sexual comments or remarks $42(41.6 \% \%)$, grabbing 44(43.6\%), pinching 38(37.6\%), sexually motivated touching, groping, or rubbing 36(35.6\%), and only $6(5.9 \%)$ were experienced rape. With growing urbanization, the phenomenon of sexual violence in cities has become a serious issue. Sexual harassment has an effect on women's mobility, accessibility, and confidence. Lack of safety and security in public spaces and public transport affects women's human rights and their ability to participate equally in the city(Sonal Shah, Kalpana Viswanath, 2017).Similar studies in Mumbai, Kerala, Guwahati, and Bengaluru showed high levels of sexual harassment and everyday violence. In a study of two cities in Kerala by Sakhi Women's Resource Center in 2010, Kozhikode reported that 71 percent of women respondents faced harassment while waiting for public transport, while 69 percent faced it while using public transport. Similarly, in Trivandrum, over 80 percent faced sexual harassment while either waiting for or riding public transport (Sakhi Women's Resource Centre, 2011). In Mumbai, a survey done by Akshara in 2013 also showed that 46 per cent of women reported facing sexual harassment inside buses and 17 percent inside trains (Sakhi Women's Resource Centre, 2011).Unlike developing countries, in developed countries such as in Britain, public transport is generally very safe and serious sexual assaults are rare. However, research has found that around $15 \%$ of women and girls have been subjected to unwanted sexual behavior on the London transport network, the vast majority of which goes unreported(Gekoski et al., 2015). This study result has also showed that $84.1 \%$ of respondents had experienced psychological violence. The common incidents that constitute psychological violence are insulting or making feel bad about oneself, 84(83.2\%), deliberate scaring or intimidating $30(29.7 \%)$, and belittling or humiliating in front of others 12(11.9\%) (see Table 3). According to a study conducted in Thiruvananthapuram and Kozhikode Cities, Kerala (Sakhi Women's Resource Centre, 2011), psychological or emotional abuse includes trauma to the victim caused by acts, threats of acts, or coercive tactics. Psychological violence occurs when psychological or emotional abuse is accompanied by physical and/or sexual violence.

The study revealed the fact that the majority of respondents have experienced more than one form of violence while using public transport services in the past one year (2018). This indicates that VAWG in the transport sector is a serious threat to women's fundamental rights, safety, and security to access their education, job, healthcare, and mobility in cities in general. However, this remains a much-neglected area with little data and few laws, policies, and initiatives to prevent and address it(Kakal \& Iyot, 2015).

\subsection{Use of Public Transport and Experience of Violence}

Among respondents those who experienced violence, more than half $53.5 \%$ of the respondents used public transport more than four times per day and 34.7\% used four times per day (see Table 4 ). This clearly shows that women's high dependency on public transportation and its significance in their lives to fulfill their productive and reproductive roles and responsibilities. On the other hand, the result indicates that the more frequently they use public transport, the more they are exposed to violence. A study conducted on female students in the Kathmandu valley of Nepal (Gautam, Sapakota, Shrestha, \& Regmi, 2019) revealed that 96.8\% of female students who travel daily found a higher chance of facing harassment in public transportation. Furthermore, it was found that traveling frequency was more likely associated with harassment. Those who occasionally used public transportation had a lower chance of being harassed compared with those who traveled on a daily basis(Gautam et al., 2019).

The findings also indicate that, among women and girls who experienced violence, $50.5 \%$ and $23.8 \%$ were travelling late in the evening and on rush hours, respectively. This indicates that most of the respondents were travelling at risk time, which can expose them to gender-based violence (see Table 4).In Malaysia, most women have to leave the house and travel alone every day, including in the early morning and late at night without being accompanied by family members or female friends, which potentially exposes them to an insecure situation, especially sexual assault by men (Abdul Jalil and Abd Rahman, 2011). Abdul Jalil and Abd Rahman(2011)stated that travelling during peak hours with male passengers and getting off at multiple destinations might expose women to unsafe situations such as dark areas of taxi stands, bus stations, and others. This finding was also mentioned in other studies (Gautam et al., 2019) and states that mornings and evenings are more unsafe times for a female in which she may face violence and sexual harassment in a bus. Morning and evening hours were the most risky times. It was found that harassment was more common in the evening $(41.39 \%)$ followed by morning $(40.46 \%)$. This is possibly due to the peak hours, and on an overcrowded bus, the perpetrator (passenger) has ample opportunity to harass. Additionally, there might be a limited number of vehicles during that time, which are at a higher risk of sexual violence. The reason behind this is that most of the males consider that they are superior socially, culturally, and physically, while females have less power compared with men. Therefore, females feel insecure when they raise their voice against harassment.12,33 (Gautam et al., 2019)The common types of public transport serving in the city are Mini bus, Bajaj (three wheel small vehicles), and city buses. Among women and girls who experienced violence in public transport, more than half (51.5\%) used a small vehicle called Bajaj as a 
means of transportation in the city. About $30.7 \%$ used Mini buses for transportation purposes. While $17.8 \%$ used City Buses (Table 4). The low usage of city buses might be due to the shortage of city buses (only 17 buses), and bus stops are also not accessible for passengers who ever want to use them.

FGD participants have given some characteristics to the available modes of public transport services. They characterized city buses as cheap, inaccessible, and overcrowded and have difficult bus stops to depart whenever commuters want to depart. Bajaj's are explained as comfortable, simple, accessible, costly, and unsafe to board alone. FGD participants also state the special features of Mini buses as overcrowded, have many routes and taxi stops that enlarge the commuter's freedom of travel to any part of the city, less expensive and safer to use at night times when compared to Bajaj's.

\subsection{Transport Facilities and Management}

Transport facilities and management is a general category that includes three attributes: respondents were asked like bus stop facilities and services, availability of public transport vehicles, and cost of public transport. Bus stop facilities and services were measured in the level of satisfaction of public transport users on the availability of all the facilities and services at bus stops to make the service safer (Table 5). In this regard, the majority (58.8\% up to $100 \%$ ) of the respondents responded that facilities and services at bus stops are, in some cases, not available or very poor. From this, we can conclude that poor facilities and services in transport systems are one of the reasons that can contribute to the VAWG. Therefore, this indicates the need to improve the facilities and services of the public transport sector as an intervention strategy to reduce VAWG. Improving facilities and services of public transport will increase the safety and sense of security of the transport system for women and girls, and at the same time decrease the level of violence.

The availability of public transport vehicles was measured in the action of loading the recommended number of passengers. Extra loading of passengers over the legally permitted number of seats indicates a shortage of public transportation, which in turn exposes women and girls to violence like unwanted sexually motivated touching, groping, or rubbing. Fig 1 shows that $94.1 \%$ of the respondents experienced overloading due to a shortage of public transport. This shows that over loading is a common phenomenon in the transport sector. According to the discussions of FGD participants, one member of FGD explained her experience as follows:

"One day I refused to permit extra loading on my seat but, the conductor's reply was amazing. He said," I know you very well. I will never let you board my taxi again. Why don 't you buy your own automobile? Is this the place where you remember your rights?" Until I reach my destination, he talked me a lot and insulted me'.

The cost of public transport was measured in the public transport users' experience of overcharging that is paying beyond the tariff set by the government while using public transport services. It is believed that the refusal of overcharging payment by women or girls might lead to a violent reply from the conductor and the driver. According to the study results as indicated in Fig.1, about 148 (81.2\%) of the respondents had experienced overcharging while using public transport services. FGD participants also explained that overcharging increased the risk of violence in women. First, overcharging becomes a problem when they use Mini buses and Bajaj, while City buses strictly implement the tariff set by the government. Second, the conductors of Mini buses are very known to force commuters to pay extra money beyond the tariff. Third, although conductors demand extra money beyond the tariff from all commuters, refusal of overcharging by women or girls has a violent reply from the conductor and the driver. This might be due to that drivers and conductors perceive women and girls as helpless. In addition, the absence of security members or traffic police at bus stops encourages conductors to request overcharging beyond the tariff.

\subsection{Factors Contributing to VAWG in the Public Transport Service}

Bivariable and multivariable binary logistic regression analyses were done to identify associations between dependent and independent variables. Crude odds ratio and adjusted odds ratio, 95\% CI and p-value were used to assess the strength of association and statistical significance, and the assumption of Hosmer and Lemeshow was checked and met ( $\mathrm{P}=0.84$ ), which is greater than 0.05 and the model accurately classify $83.4 \%$ cases. Those Variables that were significant in Bivariable analysis were entered the multivariable analysis in order to control for confounding variables.

Related with age of the women, Age categories of 15-29 years were 4.1 times more likely to face GBV as compared those age category of $45-60$ years $(A O R=4.128,95 \% \mathrm{CL}: 1.167,14.602)$. This implies that the younger the age, the more they are exposed to violence (Table 6). This finding is similar to the finding in Azerbaijan,where younger women, especially those aged 15 - 30, were more likely to be harassed than women aged older(Asian Development Bank, 2015).

Single women were a 4.8 times higher risk of GBV during transportation than compared to separated women "AOR" = $(4.840$, CI 95\%: 1.038, 22.557). Time of travel using public transport has a significant association with the GBV of women. Women uses mid-day and rush hour were negatively associated with GBV, and women who 
used transportation during the late evening were positively associated, that is, who women used public transportation during the late evening were 3.6 times more likely to face GBV as compared to morning time $(\mathrm{AOR}=3.614,95 \% \mathrm{CI}: 1.999,13.157)$ (Table 6).

Regarding the types of transportation, women who usually use Bajaj ( three wheels) were 14 times more likely of face GBV as compared the city bus $(\mathrm{AOR}=14.32195 \% \mathrm{CI}: 3.308,62.001)$. The availability of light in the evening at Bus stop \& on the road protects women from GBV. Since women who usually use transportation methods with availability of light in the evening at Bus stop were $77.2 \%$ less likely of have GBV (AOR=0.228, $95 \% \mathrm{CI}: 0.065,0.799)$. Extra loading of people during transportation is also significantly associated with the GBV of women; women Experiencing extra loading due to shortage of seats were 19 times more likely to face as compared to that of the appropriate number of loading to the transportation care AOR $=19.674,95 \%$ CI 3.870 , 100.025), but overcharging beyond appropriate tariff is not significantly contribute to GBV in the multivariable analysis (Table 6).

\section{Conclusions}

A change in the social status of women is much more dependent on their empowerment status in education, income, political participation, decision-making power, and other important and factors of development. It should also be very clear that our effort to achieve gender equality would not be successful until we act similarly to combat VAWG in each and every aspect of women's and girl's lives. Combating violence in the private sphere will not be fruitful unless the VAWG in the public sphere is also taken seriously too.

The major findings of this study have shown a high risk of safety and security for women's and girl's when traveling in public transport. Demographic, physical, legal, and community factors have been identified as factors contributing to VAWG in public transport. Although women and girls have the legal right to move freely in public spaces, this can only be achieved by a change in the behavior of the community. Keeping in mind the long-term interventions that can bring behavioral change, the concerned stakeholders should focus on developing gendersensitive public transport service plans and policies that consider the special needs, safety, and security of women and girls and also should focus on taking actions that help women and girls to avoid any forms of violence in public transport. Thus, we need to give emphasis to increasing the safety and security of women and girls in the public transport sector, which is the main enabler for women and girls to access their work, education, and other important social, economic, and political activities.

\section{References}

Abdul Jalil, N., \& Abd Rahman, T. M. A. (2011). Women's rights regarding safety in public transport-in the eye of Islam : an analysis . 2011 International Conference on Social Scince Humanity, 5, 221-224.

ActionAid. (2011). Examining the Gender Impact of Violence and Urbanisation: A Comparative study of Brazil, Cambodia, Ethiopia, Liberia and Nepal. In Women and the City. https://doi.org/10.1080/13604810903529217

Aliyaa, S., Hassan, R. M., \& Komsan, N. A. (2008). " Clouds in Egypt 's Sky " Sexual Harassment: from Verbal Harassment to Rape.

Aloul, S., Naffa, R., \& Mansour, M. (2019). Gender in Public Transportation: A Perspective of Women Users of Public Transportation. Retrieved from www.fes-jordan.org

Asian Development Bank. (2015). Policy brief: A safe public transportation environment for women and girls. Retrieved from Asian Development Bank website: https://www.adb.org/sites/default/files/projectdocument/152881/44067-012-tacr-19.pdf

Australian Bureau of Statistics. (2009). Australian Social Trends, 2008, Chapter - Complementary therapies. Retrieved from Commonwealth of Australian website: http://www.abs.gov.au/AUSSTATS/abs@.nsf/Lookup/4102.0Chapter5202008

Choudhary, M., Dube, S., \& Verma, R. (2018). Women safety in public transport. 8(162), 162-170.

Divall, C., \& Bond, W. (2017). Suburbanizing the Masses: Public Transport and Urban Development in Historical Perspective. Retrieved from https://www.crcpress.com/Suburbanizing-the-Masses-Public-Transport-andUrban-Development-in-Historical/Divall-Bond/p/book/9781138711563

Ethiopia Central Statistical Agency. (2016). Ethiopian Demographic Health Survey 2016.

Farida, I. (2018). Public transport service relating to safety. IOP Conference Series: Materials Science and Engineering, 434(1). https://doi.org/10.1088/1757-899X/434/1/012195

Fraser, E., Viswanath, K., \& Maclean, L. (2017). Violence against Women and Girls, Infrastructure and Cities. Retrieved from https:/www.gov.uk/government/publications/violence-against-women-andgirls-\%2509infrastructure-and-cities-briefing-note

Gautam, N., Sapakota, N., Shrestha, S., \& Regmi, D. (2019). Sexual harassment in public transportation among female student in Kathmandu valley. Risk Management and Healthcare Policy, 12, 105-113.

Gekoski, B. A., Gray, J. M., Horvath, M. A. H., Edwards, S., Emirali, A., \& Adler, J. R. (2015). 'What Works' in Reducing Sexual Harassment and Sexual Offences on Public Transport Nationally and Internationally: A 
Rapid Evidence Assessment. (February).

IASC. (2017). Interagency-GBV-Case-Management-Guidelines_Final_2017. Retrieved from http://www.gbvims.com/wp/wp-content/uploads/Interagency-GBV-Case-ManagementGuidelines_Final_2017.pdf

ITF, iNTERNATTIONĀL T. F. (2018). Women's Safety and Security A Public Transport Priority. Retrieved from www.itf-oecd.org

Jafarova, T., Campbell, S., \& Rojas, W. S. (2014). AZE: Rapid Assessment on Sexual Harassment in the Baku Metro Rail Technical Assistance Consultant 's Final Report.

Jaramillo, J. J. (2014). Undercover cops for sexual assault Bogotá police crack down on sexual assault on public buses. Retrieved

from http://www.slate.com/blogs/xx_factor/2014/08/01/undercover_cops_for_sexual_assault_bogot_police_crac k_down_on_sexual_assault.html

Kakal, Z., \& Iyot, C. (2015). TRANSPORT AND WOMEN' S SAFETY. Re-Thinking Women's Safety in the Intermediate Public Transportation Sector, (April), 8. EMBARQ.

Korn, J. (2018). Riding Scared: Sexual Violence and Women's Mobility on Public Transportation in Santiago , Chile Riding Scared: Sexual Violence and Women's Mobility on Public.

Mineta Transportation Institute. (2009). How to Ease Women's Fear of Transportation Environments : Case Studies and Best Practices.

Mungai, M. wa, \& Samper, D. A. (2006). "No Mercy, No Remorse”: Personal Experience Narratives about Public Passenger Transportation in Nairobi, Kenya. Africa Today, Volume 52(Number 3, Spring 2006), 51-81. https://doi.org/10.1353/at.2006.0033

Rahman, M. S. (2010). Bus Service for 'Women Only' in Dhaka City : An Investigation. Journal of Bangladesh Institute of Planners, 3(December), 17-32.

Sakhi Women's Resource Centre. (2011). Are cities in Kerala safe for Women? Safe City free of Violence Against Women and Girls Initiative Summary of the study. 1-40.

Sham, R., Omar, N., \& Dia Widyawati, A. (2018). Women and Crime in Central Business District Area. Asian Journal of Behavioural Studies, 3(9), 207. https://doi.org/10.21834/ajbes.v3i9.74

Sonal Shah, Kalpana Viswanath, S. V. and S. G. (2017). Women and Transport in Indian Cities.

THE WORLD BANK. (2016). Preventing Violence Against Women in Transport Systems. Feature Story, p. 1. Retrieved from http:/www.worldbank.org/en/news/feature/2016/03/08/preventing-violence-againstwomen-in-transport-systems

UN Women. (2013). ENDING VIOLENCE AGAINST WOMEN AND GIRLS : PROGAMMING ESSENTIALS III . Main Strategies to End Violence against Women and Girls I . Overview of Violence against Women and Girls What is Violence against Women and Girls? Global Report. Retrieved from http://www.endvawnow.org/uploads/modules/pdf/1372349234.pdf

UN Women. (2014). Ensuring safe and secure public transport for women and girls. In International Transport Forum. $\quad$ Retrieved from https://unwomen.org.au/wpontent/uploads/2017/05/UNW safe public transport.pdf

United Nations. (2015). Transforming our world: the 2030 Agenda for Sustainable Development. United Nations Sustainable knowledge platform. Sustainable Development Goals, 1-40a. https://doi.org/https://sustainabledevelopment.un.org/post2015/transformingourworld

WEL. (2015). ASSESSMENT ON THE MAGNITUDE OF VIOLENCE AGAINST WOMEN AND GIRLS. Retrieved from https://www.daogewe.org/index.php/publications/reports/43-violence-against-women-\%2509andgirls-in-public-transport-by-wel/file 
Table 1 Socio-demographic characteristics of respondents $(\mathrm{N}=199)$

\begin{tabular}{llrr}
\hline Attribute & Responses & Total & \%req. \\
\cline { 2 - 3 } Age category & & 122 & 61.3 \\
& $15-29$ & 62 & 31.2 \\
& $30-44$ & 15 & 7.5 \\
& $45-60$ & 48 & \\
Max. & 16 & \\
Marital status & Min. & 28.29 & 50.8 \\
& Ave. & 101 & 35.2 \\
Education & Single & 70 & 14.1 \\
& Married & 28 & 3.5 \\
& Separated & 7 & 6.5 \\
& No formal education & 13 & 39.9 \\
& Primary & 79 & 19.6 \\
& Secondary & 39 & 30.7 \\
\hline
\end{tabular}

Table 2 Types of VAWG in public transport services $(\mathrm{N}=101)$

\begin{tabular}{llrr}
\hline SN & Types of VAWG in public transport* & Frequency & \% \\
\hline 1 & Physical violence & 75 & 74.3 \\
2 & Sexual violence & 87 & 86.1 \\
3 & Psychological violence & 84 & 83.2 \\
\hline
\end{tabular}

* Each types of VAWG was weighted out of the total respondents experienced violence

Table 3 Common Types of Incidents Experienced $(\mathrm{N}=101)$

\begin{tabular}{|c|c|c|}
\hline Common Types of Incidents* & Frequency & $\%$ \\
\hline \multicolumn{3}{|l|}{ Physical Violence } \\
\hline Dragging & 61 & 60.4 \\
\hline Throwing something that could hurt a woman & 45 & 44.6 \\
\hline Coercion to board against one's wish & 41 & 40.6 \\
\hline Push shoving and pulling hair or cloth & 13 & 12.9 \\
\hline \multicolumn{3}{|l|}{ Sexual Violence } \\
\hline Staring & 68 & 67.3 \\
\hline Making noise, whistling or cat calling & 50 & 49.5 \\
\hline Sexual comments or remarks & 42 & 41.6 \\
\hline Grabbing & 44 & 43.6 \\
\hline Pinching & 38 & 37.6 \\
\hline Sexually motivated touching, groping or rubbing & 36 & 35.6 \\
\hline Rape & 6 & 5.9 \\
\hline \multicolumn{3}{|l|}{ Psychological Violence } \\
\hline insulting or making feel bad about oneself & 84 & 83.2 \\
\hline deliberate scaring or intimidating & 30 & 29.7 \\
\hline belittling or humiliating in front of others & 12 & 11.9 \\
\hline
\end{tabular}

* Each types of incident was weighted out of the total respondents experienced violence 
Table 4 Public transport usage versus experience of violence $(\mathrm{N}=101)$

\begin{tabular}{llrr}
\hline Attribute & Responses & Experienced Violence \\
\hline & & Frequency & \% \\
\hline \multirow{3}{*}{ Frequency of traveling per day } & More than 4 times & 54 & 53.5 \\
& 4 times & 35 & 34.7 \\
& 3 times & 7 & 6.9 \\
& 2 times & 5 & 4.9 \\
\hline \multirow{3}{*}{ Time of travelling } & Rush hours (7:00-9:00AM \& 4:00-6:00PM) & 24 & 23.8 \\
& Midday (12:00-2:00PM) & 5 & 4.9 \\
& Early in the morning (5:00-6:30AM) & 21 & 20.8 \\
& Late in the evening (After 8:00 PM) & 51 & 50.5 \\
\hline Type of public transport used & Mini bus & 31 & 30.7 \\
& Bajaj & 52 & 51.5 \\
& City Bus & 18 & 17.8 \\
\hline
\end{tabular}

Table 5. Bus Stop Facilities and Services $(\mathrm{N}=199)$

\begin{tabular}{llrr}
\hline Attributes & Responses & Frequency & \% \\
\hline \multirow{2}{*}{ Availability of light in the evening at Bus stop \& on the road } & No & 150 & 75.4 \\
Availability of shelter at bus stops & No & 49 & 24.6 \\
& No & 199 & 100.0 \\
Availability of full information about routes and tariffs & Yes & 192 & 96.5 \\
Keeping cleanness of the transport & No & 7 & 3.5 \\
Presence of security members or traffic police at Bus stop & No & 199 & 100.0 \\
& Yes & 117 & 58.8 \\
Presence of a system to treat travellers who need special care & No & 82 & 41.2 \\
& Yes & 194 & 97.5 \\
\end{tabular}


Table 6 Factors Contributing to VAWG in Public Transport $(\mathrm{N}=199)$

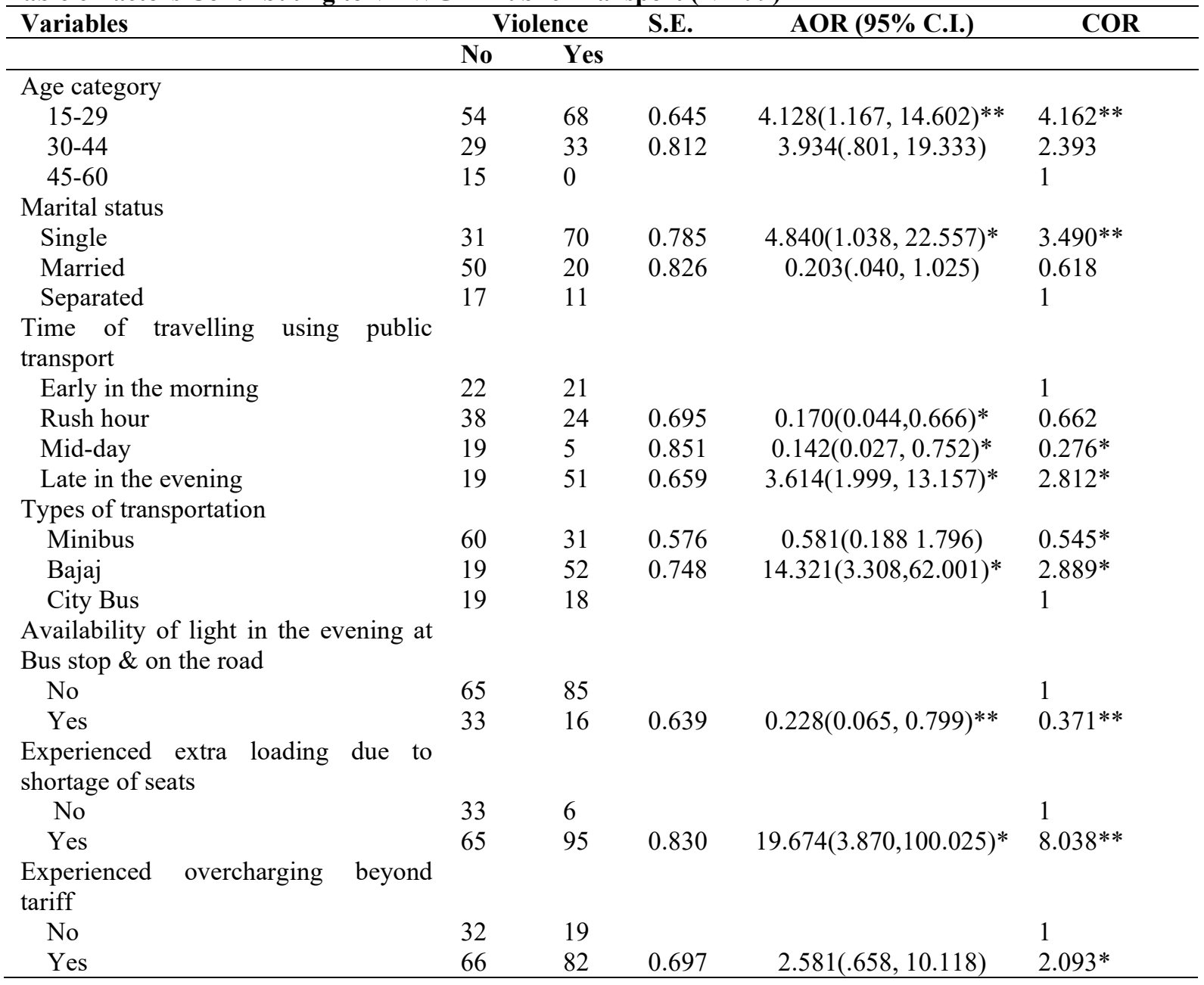

\section{Problems Faced due to Shortage of Public Transport}

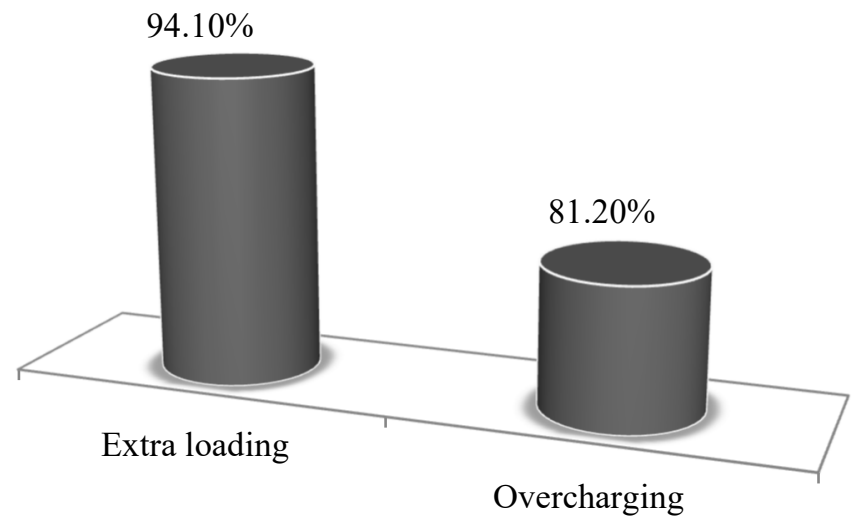

Figure 1: Women and Girls Experienced Extra Loading and Overcharging 